\title{
Editorial
}

\section{Bloodstream Infection: An Ounce of Prevention Is a Ton of Work}

\author{
Nasia Safdar, MD, MS
}

\begin{abstract}
Bloodstream infection (BSI) remains the most important infectious complication of vascular access and is associated with prolonged hospital stay, ${ }^{1-4}$ increased costs, ${ }^{1,2,4}$ and, in some studies, attributable mortality. ${ }^{13,5}$ Prevention of BSI is essential, especially in patients requiring long-term vascular access for chemotherapy, parenteral nutrition, or hemodialysis. This issue of Infection Control and Hospital Epidemiology includes several articles about BSI: two evaluate novel anti-infective lock solutions for intravascular device-related BSI, ${ }^{6,7}$ one discusses barriers to the implementation of evidence-based recommendations for prevention of intravascular device-related BSI, ${ }^{8}$ one describes the outcomes of Staphylococcus aureus BSI in patients undergoing hemodialysis, ${ }^{9}$ and one evaluates excess mortality and costs associated with candidemia. ${ }^{10}$

Recent advances in our understanding of the pathogenesis of intravascular device-related BSI have led to the development of effective strategies for prevention. ${ }^{11-13}$ For long-term devices, it has been shown that the most common route of infection is intraluminal (ie, at the time of insertion or in the days following, microorganisms contaminate the hub [and lumen] of the intravascular device when the intravascular device is inserted over a percutaneous guidewire or later manipulated). ${ }^{14-16} \mathrm{~A}$ promising approach has involved instilling, or locking, an anti-infective solution into the device lumen to prevent colonization of the intraluminal surface by suspended planktonic-phase contaminants. ${ }^{17-19}$ In a meta-analysis of seven randomized, controlled trials, a vancomycin-heparin lock or flush solution was found to considerably reduce the risk of intravascular device-related BSI when compared with a heparin solution alone. ${ }^{20}$ There remains concern that a vancomycin-
\end{abstract}

containing lock solution may promote the emergence of vancomycin-resistant organisms, although this is unlikely due to the infinitesimal quantities of vancomycin used. A surge in research exploring anti-infective lock solutions for the prevention and treatment of intravascular device-related BSI has led to the development of several new agents. Novel agents that have shown promise in case reports, pilot studies, or small clinical trials include, among others, taurolidine, ${ }^{21}$ gentamicin-citrate, ${ }^{22}$ minocycline-ethylenediaminetetraacetic acid (EDTA), ${ }^{23}$ and ethanol. ${ }^{24}$

In this issue of Infection Control and Hospital Epidemiology, Percival et al. report their findings regarding the efficacy of yet another novel lock solution, tetrasodium EDTA, for eradicating biofilms in an in vitro model system. ${ }^{6}$ They found that tetrasodium EDTA effectively eradicated (ie, no growth at the lower limit of detection) biofilms of $S$. epidermidis, Pseudomonas aeruginosa, Klebsiella pneumoniae, or Escherichia coli after 21 hours of lock treatment with $4 \mathrm{~mL}$ of a $40-\mathrm{mg} / \mathrm{mL}$ solution; eradication of biofilms of methicillin-resistant $S$. aureus or Candida albicans required a further 4 hours of treatment with a fresh lock solution. The study was limited by the fact that the biofilms studied were immature and lacked the complexity of in vivo biofilms and that there are no published data on the microbicidal activity of tetrasodium EDTA to make a strong case for its superiority over other lock solutions being studied. The same group of authors previously published a study of the efficacy of tetrasodium EDTA for eradication of biofilms developed in vivo and recovered from explanted catheters, which more closely approximates the clinical setting. ${ }^{25}$ Nonetheless, the results of the current study are intriguing 
and should lead to further assessment of the utility of this novel lock solution.

Bleyer et al. report the results of a pilot doubleblind, randomized, controlled trial comparing minocycline-EDTA with a placebo for the prevention of intravascular device-related BSI in 60 patients undergoing hemodialysis with central venous catheters. ${ }^{7}$ A single episode of intravascular device-related BSI occurred in the study in the heparin group. As the authors point out, a strong placebo effect was noted, and the study lacked the power to meet the primary endpoint regarding intravascular device-related BSI. Catheter colonization was markedly different in the treatment and placebo groups. However, the study was limited by the fact that cultures were performed at removal for only 14 of 30 catheters in the heparin group and 11 of 30 catheters in the minocycline-EDTA group. Marked improvement in overall catheter survival was found in the minocyclineEDTA group compared with the placebo group (83\% and $66 \%$, respectively); however, the incidence of catheter clotting was the same in the two groups. The favorable results from this trial suggest that this agent should be tested in a larger prospective, randomized trial.

In recent years, several randomized, controlled trials of preventive strategies for intravascular devicerelated BSI have been conducted, and measures such as chlorhexidine for cutaneous antisepsis ${ }^{26}$ and maximal barrier precautions for the insertion of intravascular devices ${ }^{27}$ have been unequivocally shown to markedly reduce the risk of intravascular device-related BSI. It also has become apparent, however, that such proof of efficacy, although necessary, is not sufficient for these and other efficacious measures to become part of clinical practice. ${ }^{28,29}$ Much attention has focused on the factors that hinder the implementation of evidence-based guidelines into practice. Many identified barriers must be removed before evidence-based guidelines can be incorporated into clinical practice with the goal of improving patient care. ${ }^{30-32}$ Several guidelines for the prevention of intravascular device-related BSI have been published, the most recent in $2002 .^{33}$

In this issue of Infection Control and Hospital Epidemiology, Rubinson et al. ${ }^{8}$ report the results of a cross-sectional survey of 1,000 physicians with the goal of identifying and characterizing self-reported barriers to the implementation of two important evidence-based recommendations for prevention of intravascular device-related BSI: maximal barrier precautions and chlorhexidine for cutaneous antisepsis. The authors used the 1996 Centers for Disease Control and Prevention guideline in their 2002 survey. Of a total sample of $1,000,178$ physicians met the criteria for participation (recent CVC insertion) in the entire survey; $42 \%$ of these physicians were residency trainees. The a priori sample size required to produce robust models in multivariable modeling as calculated by the authors was not met regarding maximal barrier precautions, and too few respondents used chlorhexidine to permit meaningful comparisons between chlorhexidine and povidone-iodine. These points notwithstanding, the authors' findings are disturbing. High outcome expectancy was associated with high adherence to maximal barrier precautions in a multivariable model. However, awareness of the Centers for Disease Control and Prevention guideline and external factors, such as lack of equipment and inconvenience, failed to reach statistical significance. The complexity of translating evidence into practice suggests that dissemination of guidelines must be supplemented by intensive efforts to ensure adherence. Barriers to adherence may differ from institution to institution, but a multifaceted, systems-based approach with strong institutional commitment has been shown to be effective for the prevention of intravascular device-related BSI ${ }^{34}$ Rubinson et al. found that feedback of BSI rates to intensive care units or physicians was not associated with high adherence; these results are different from those reported elsewhere ${ }^{35}$ and may be related to the small numbers of institutions that did any kind of reporting of BSI rates. Changing physician behavior continues to be a challenge, and more research is needed in this important area.

Patients with end-stage renal disease who require hemodialysis are at extremely high risk of $S$. aureus bacteremia. ${ }^{36,37}$ Engemann et al. undertook a descriptive study of the clinical outcome of 210 patients undergoing hemodialysis who had S. aureus bacteremia 12 weeks following the bacteremia. ${ }^{9}$ Because the study did not contain an unexposed group (patients without $S$. aureus bacteremia), it was not possible to determine the mortality attributable to this infection. Of the 210 patients who comprised the study population, 165 (78.6\%) were African American; the mean duration of dialysis was 2.9 years. A troubling finding was that the most frequent hemodialysis access was a tunneled, cuffed intravascular catheter (55.7\%) rather than a fistula or graft, which are associated with much lower rates of BSI. ${ }^{38}$ Not unexpectedly, the major source of BSI was hemodialysis access (88\%) and a considerable proportion of BSI episodes were caused by methicillin-resistant $S$. aureus (33\%), which, in a recent study by the same group of investigators, was shown to be associated with fivefold higher mortality compared with methicillin-sensitive $S$. aureus among patients undergoing hemodialysis. ${ }^{39}$ Thirty-one percent of the patients suffered complications, the most frequent of which was infective endocarditis (17\%).

The authors carefully measured relevant costs for 143 patients for whom cost data were available and estimated that the mean cost of treating an episode of $S$. aureus bacteremia was $\$ 24,034$. An effective way to greatly reduce the incidence of $S$. aureus bacteremia among patients undergoing hemodialysis would be to expeditiously create a fistula or implant a graft as soon as it becomes apparent that long-term hemodialysis will be necessary. Unfortunately, a recent annual survey from the Centers for Disease Control and Prevention found that the percentage of patients undergoing long-term hemodialysis with a catheter increased from $12.7 \%$ in 1995 to $24.0 \%$ in 2000.40

Candida species have emerged as a major nosocomial pathogen and, according to data from the National Nosocomial Infections Surveillance System, are the fourth 
most common cause of BSI in the United States. ${ }^{41}$ Morgan et al. performed a large matched cohort study comparing patients who had candidemia with those who did not matched on age, hospital type, year of admission, discharge diagnoses, and duration of hospitalization before the onset of candidemia. ${ }^{10}$

Exposed patients were identified through laboratory surveillance in Baltimore and Baltimore County, Maryland, and Connecticut during 1998 to 2000; the non-exposed group comprised hospitalized patients without candidemia. The excess mortality due to candidemia was $19 \%$ in Connecticut and $24 \%$ in Baltimore and Baltimore County. However, when treatment was taken into account in the multivariable analysis, adequate treatment (defined by the authors as any systemic antifungal given for 7 days after the first blood culture positive for candidemia) was associated with a $50 \%$ to $60 \%$ reduction in mortality. The time frame for measuring mortality was not provided. This information is important to determine a temporal relationship between candidemia and mortality when assessing causality. The lack of data regarding microbiology and source of candidemia is a limitation of the study, as these factors may influence morbidity and mortality. Due to the unavailability of data, the investigators were not able to match on or adjust for severity of illness, an important confounding factor.

It is puzzling and unexplained that a considerable number of patients with candidemia did not receive treatment (39\% of 178 patients from Connecticut and $30 \%$ of 257 patients from Baltimore and Baltimore County). This study predates the widespread availability of the new agents caspofungin and voriconazole and it will be interesting to discover, in future studies, whether these novel agents have an impact on survival from candidemia.

Morgan et al. provide useful data on the economic outcomes of candidemia. The investigators measured total hospital charges and calculated costs using cost-to-charge ratios and compared these data with those for a baseline patient (a patient who did not have candidemia, did not require critical care, and was 30 to 39 years old). Treatment of candidemia (but not candidemia per se) was associated with an increased hospital stay of 7 to 18 days and increased costs of approximately $\$ 7,000$ to $\$ 25,000$.

The morbidity and mortality associated with BSI emphasize the importance of continued efforts for prevention. Adherence to evidence-based recommendations is essential. In addition, novel technology, such as anti-infective lock solutions, for the prevention of intravascular device-related BSI offers great promise and should be explored further.

\section{REFERENCES}

1. Arnow PM, Quimosing EM, Beach M. Consequences of intravascular catheter sepsis. Clin Infect Dis 1993;16:778-784.

2. Pittet D, Tarara D, Wenzel RP. Nosocomial bloodstream infection in critically ill patients: excess length of stay, extra costs and attributable mortality. JAMA 1994;271:1598-1601.

3. Collignon PJ. Intravascular catheter associated sepsis: a common problem. The Australian Study on Intravascular Catheter Associated Sepsis. Med J Aust 1994;161:374-378

4. Rello J, Ochagavia A, Sabanes E, et al. Evaluation of outcome of intravenous catheter-related infections in critically ill patients. Am J Respir
Crit Care Med 2000;162:1027-1030.

5. Smith RL, Meixler SM, Simberkoff MS. Excess mortality in critically ill patients with nosocomial bloodstream infections. Chest 1991;100:164167.

6. Percival SL, Kite P, Eastwood K, et al. Tetrasodium EDTA as a novel central venous catheter lock solution against biofilm. Infect Control Hosp Epidemiol 2005;26:515-519.

7. Bleyer AJ, Mason L, Russell G, Raad II, Sherertz RJ. A randomized, controlled trial of a new vascular catheter flush solution (minocycline-EDTA) in temporary hemodialysis access. Infect Control Hosp Epidemiol 2005;26:520-524.

8. Rubinson L, Wu AW, Haponik EF, Diette GB. Why is it that internists do not follow guidelines for preventing intravascular catheter infections? Infect Control Hosp Epidemiol 2005;26:525-533.

9. Engemann JJ, Friedman JY, Reed SD, et al. Clinical outcomes and costs due to Staphylococcus aureus bacteremia among patients receiving long-term hemodialysis. Infect Control and Hospital Epidemiol 2005;26:534-539.

10. Morgan J, Meltzer MI, Plikaytis BD, et al. Excess mortality, hospital stay, and cost due to candidemia: a case-control study using data from population-based candidemia surveillance. Infect Control Hosp Epidemiol 2005;26:540-547.

11. Maki DG, Mermel LA. Infections due to infusion therapy. In: Bennet JV, Brachman PS, eds. Hospital Infections. Philadelphia: LippincottRaven; 1998:689-724.

12. Safdar N, Maki DG. The pathogenesis of catheter-related bloodstream infection with noncuffed short-term central venous catheters. Intensive Care Med 2004;30:62-67.

13. Crnich CJ, Maki DG. The promise of novel technology for the prevention of intravascular device-related bloodstream infection: II. Longterm devices. Clin Infect Dis 2002;34:1362-1368.

14. Sitges-Serra A, Puig P, Linares J, et al. Hub colonization as the initial step in an outbreak of catheter-related sepsis due to coagulase negative staphylococci during parenteral nutrition. JPEN J Parenter Enteral Nutr 1984;8:668-672.

15. Raad I, Costerton W, Sabharwal U, Sacilowski M, Anaissie E, Bodey GP. Ultrastructural analysis of indwelling vascular catheters: a quantitative relationship between luminal colonization and duration of placement. J Infect Dis 1993;168:400-407.

16. Garland JS, Alex CP, Mueller CD, et al. A randomized trial comparing povidone-iodine to a chlorhexidine gluconate-impregnated dressing for prevention of central venous catheter infections in neonates. Pediatrics 2001;107:1431-1436.

17. Bouza E, Burillo A, Munoz P. Catheter-related infections: diagnosis and intravascular treatment. J Chemother 2001;13:224-233.

18. Carratala J. Role of antibiotic prophylaxis for the prevention of intravascular catheter-related infection. Clin Microbiol Infect 2001;7 (suppl 4):83-90.

19. Capdevila JA. Catheter-related infection: an update on diagnosis, treatment, and prevention. Int I Infect Dis 1998;2:230-236.

20. Safdar N, Maki D. The use of vancomycin lock and flush solutions for the prevention of catheter-related bloodstream infection. Presented at the 15th Annual Meeting of the Society for Healthcare Epidemiology of America; April 17-20, 2004; Philadelphia, PA.

21. Jurewitsch B, Lee T, Park J, Jeejeebhoy $K$. Taurolidine $2 \%$ as an antimicrobial lock solution for prevention of recurrent catheter-related bloodstream infections. JPEN J Parenter Enteral Nutr 1998;22:242244.

22. Dogra GK, Herson H, Hutchison B, et al. Prevention of tunneled hemodialysis catheter-related infections using catheter-restricted filling with gentamicin and citrate: a randomized controlled study. J Am Soc Nephrol 2002;13:2133-2139.

23. Chatzinikolaou I, Zipf TF, Hanna H, et al. Minocycline-ethylenediaminetetraacetate lock solution for the prevention of implantable port infections in children with cancer. Clin Infect Dis 2003;36:116119.

24. Maki DG, Crnich CJ, Safdar N. Ethanol lock solution for prevention of recurrent IVDR BSI. Presented at the Interscience Conference on Antimicrobial Agents and Chemotherapy; September 14-17, 2003; Chicago, IL.

25. Kite P, Eastwood K, Sugden S, Percival SL. Use of in vivo-generated biofilms from hemodialysis catheters to test the efficacy of a novel antimicrobial catheter lock for biofilm eradication in vitro. J Clin $\mathrm{Mi}$ crobiol 2004;42:3073-3076.

26. Chaiyakunapruk N, Veenstra DL, Lipsky BA, Saint S. Chlorhexidine compared with povidone-iodine solution for vascular catheter-site care: a meta-analysis. Ann Intern Med 2002;136:792-801.

27. Raad II, Hohn DC, Gilbreath BJ, et al. Prevention of central venous catheter-related infections by using maximal sterile barrier precautions during insertion. Infect Control Hosp Epidemiol 1994;15:231238 . 
28. Berenholtz SM, Pronovost PJ. Barriers to translating evidence into practice. Curr Opin Crit Care 2003;9:321-325.

29. Maue SK, Segal R, Kimberlin CL, Lipowski EE. Predicting physician guideline compliance: an assessment of motivators and perceived barriers. American Journal of Managed Care 2004;10:383-391.

30. Cabana MD, Rand CS, Powe NR, et al. Why don't physicians follow clinical practice guidelines? A framework for improvement. JAMA 1999;282:1458-1465.

31. Pathman DE, Konrad TR, Freed GL, Freeman VA, Koch GG. The awareness-to-adherence model of the steps to clinical guideline compliance: the case of pediatric vaccine recommendations. Med Care 1996;34:873-889.

32. Davis DA, Thomson MA, Oxman AD, Haynes RB. Changing physician performance: a systematic review of the effect of continuing medical education strategies. JAMA 1995;274:700-705.

33. O'Grady NP, Alexander M, Dellinger EP, et al. Guidelines for the prevention of intravascular catheter-related infections. MMWR 2002;51 (RR-10):1-29.

34. Berenholtz SM, Pronovost PJ, Lipsett PA, et al. Eliminating catheterrelated bloodstream infections in the intensive care unit. Crit Care Med 2004;32:2014-2020.

35. Rosenthal VD, Guzman S, Pezzotto SM, Crnich CJ. Effect of an infection control program using education and performance feedback on rates of intravascular device-associated bloodstream infections in intensive care units in Argentina. Am J Infect Control 2003;31:405409.

36. Dopirak M, Hill C, Oleksiw M, et al. Surveillance of hemodialysisassociated primary bloodstream infections: the experience of ten hospital-based centers. Infect Control Hosp Epidemiol 2002;23:721724.

37. Sexton DJ. Vascular access infections in patients undergoing dialysis with special emphasis on the role and treatment of Staphylococcus aureus. Infect Dis Clin North Am 2001;15:731-742, vii.

38. Tokars JI. Bloodstream infections in hemodialysis patients: getting some deserved attention. Infect Control.Hosp Epidemiol 2002;23:713715 .

39. Reed SD, Friedman JY, Engemann JJ, et al. Costs and outcomes among hemodialysis-dependent patients with methicillin-resistant or methicillin-susceptible Staphylococcus aureus bacteremia. Infect Control Hosp Epidemiol 2005;26:175-183.

40. Tokars JI, Frank M, Alter MJ, Arduino MJ. National surveillance of dialysis-associated diseases in the United States, 2000. Semin Dial 2002;15:162-171.

41. Richards MJ, Edwards JR, Culver DH, Gaynes RP. Nosocomial infections in medical intensive care units in the United States. Crit Care Med 1999;27:887-892. 